\title{
The Effects of Manual Material Handling Equipment on Loading and Unloading Time of a Case on a Pallet
}

\section{Palet Üzerinde Yer Alan Bir Kolinin Boşaltma ve Yükleme Sürelerine Manüel Malzeme Elleçleme Araçalarının Etkileri}

\author{
Ömer Öztürkoğlu, Yaşar Üniversitesi, Türkiye, omer.ozturkoglu@yasar.edu.tr
}

\begin{abstract}
In this study, we mainly investigate the effect of usage of a raisable turntable as a material handling equipment on loading and unloading time to handle a box on a pallet. For this, we compared expected time to pick (extract) cases from a pallet in two different systems: pallets with turntable and pallets without turntables. We develop a varying picking time expression with respect to the human factors and the positions of cases on a pallet to formulate expected picking time. We also conduct a detailed experimental design to investigate the effects of several parameters such as pick list size and number of cases on a pallet on picking time. We show that human factors and picking from different positions, as well as number of picks, have an important impact on extracting time of cases. Therefore, we present that using turntable for picking or loading operation offers time savings over traditional manual picking from a pallet in most cases.
\end{abstract}

Keywords: Material Handling, Turntable, Deterioration, Ergonomics, Warehouse.

Öz: Bu çalışmada, malzeme elleçleme ekipmanlarından olan yükseltilebilir döner tabla kullanımının palet üsütnde yer alan bir kolinin boşaltma veya yükleme süresine olan etkisi araștırılmaktadır. Bunun için, iki farklı sistemde palet üzerinden alınan kolilerin beklenen toplama (veya çıkartma) süresi karşılaş̧tırılmıştır. Bu iki sistem; döner tablalı ve döner tablasız palet yükün bulunduğu sistemlerdir. Beklenen toplama süresini elde etmek için palet üzerinde bulunan kolilerin posizyonlarını ve ergonomik koşulları dikkate alan toplama zamanı denklemleri geliştirilmiştir. Ayrıca, sipariş büyüklügü ve tam yük bir palette bulunan koli sayısı gibi bazı parametrelerin etkisini araştırmak açısından detaylı bir deneysel tasarım icra edilmiştir. Bunun sonucunda, insan faktörlerinin, toplanan kolilerin pozisyonlarının ve bir seferde toplanan koli saylsının koli toplama süresi üzerinde önemli bir faktör olduğu gösterilmişstir. Bununla birlikte, koli toplama ve yükleme operasyonlarında yükseltilebilir döner tabla kullanımının geleneksel manuel toplamaya göre bir çok durumda koli toplama süresinde iyileștirme sunduğu gösterilmiştir.

Anahtar Kelimeler: Malzeme Elleçleme, Döner Tabla, Eskime, Ergonomi, Depo

\section{Introduction}

Unit-load picking and multiple-case picking (called order picking) are the two of the main operations in a distribution center where the storage area is the major section of it. According to Frazelle (1996), order picking has very important portion, approximately 55\%, of the warehouse operating costs. In order to increase the efficiency of order picking and decrease the related costs with it, many distribution centers divide their storage area into two main sections: a forward-picking area (or a fast-pick area) and a reserve area (or bulk storage). As the forward picking area is utilized for efficient pick, the reserve area is used to replenish the forward-picking area when a pallet is empty. As workers perform a multiple pick from multiple locations (order picking) in a forward-picking area, they mostly perform a unit-load picking in the reserve area. There are two main cases to define these areas in a distribution center (Bartholdi \& Hackman, 2014):

- Forward-picking area has the pallet locations at the ground floor (the lowest-level of the storage area) and the reserve area comprises of the all higher levels of these pallet locations.

- The forward-picking area and the reserve area are designed in different sections of the warehouse. Forward-picking area includes all pallet locations in the pallet flow rack and the reserve area is usually 6-pallet high rack.

According to deKoster et al. (2007), low-level, picker-to-parts order picking systems form the majority of picking systems in warehouses around the world (over $80 \%$ in Western Europe). Because of this reason, we focus on this type of forward-picking area in our study to analyze the order picking operation. In these systems, a worker picks items (usually cases) from pallet locations at the ground level. When a pallet is empty in a location, a unit-load is moved from reserve are to the location. Hence, workers travel through the storage locations to fulfill their customer or replenishment orders. Tompkins et al. (2003) showed that even though travel is the most dominant factor on order picking operation, picking time (or extraction time) accounts for about $15 \%$ of the operational cost because it is mainly done by workers. Therefore, in our study we determined our performance measure as extraction time of cases from a pallet.

In literature, there are a few number of studies relevant to picking (extraction) time from pallet locations. Gademann et al. (2001) and Gademann \& van de Velde (2005) accounted for fixed and uniformly distributed extraction time per pick in their model. Gademann et al. (2001) also developed a model for solving the order batching problem in a wave picking environment with the objective of minimization of the maximum lead time of the batches. They specified that the extraction time is a significant factor on lead time of a batch when there is a small number of aisles. They also mentioned that the lead time of a batch is mainly determined by travel time if the extraction time is relatively small. Gademann \& van de Velde (2005) also addressed that the extraction time may be omitted in the optimization problem because it is constant and 
independent of the composition of a batch. However, as we know that humans are not $100 \%$ consistent due to learning effect, physical and physiological limits, and psychological issues. Therefore, in our study we assume that picking time is not constant.

Jones \& Battieste (2004) addressed that labor picking efficiency can be improved by assigning fast-moving items to better locations where workers can easily reach. Pick-face in front of the picker in a pallet flow rack or the SKUs that are located at the height between the picker's waist and shoulders can be described golden zones. Hence, these locations are expected to alleviate some occupational problems and worker fatigue, as well as fast picking. Petersen et al. (2005) consider pick time as the combination of extracting of SKUs from their storage locations, unloading them to the pickup-and-deposit (P\&D) point and other administrative activities such as labeling and barcoding. Their simulation results showed that golden zone storage assignment proposes savings in order fulfillment time compared to storage assignment policies that ignore golden zone concept. Saccomano (1996) mentioned that the time to extract a SKU from a pallet location is dependent on the height of the storage location, as well as the size and the weight of the SKU. In order to increase the efficiency of the extraction operation, Saccomano (1996) suggested that picking activity can be maximized near golden zone by reducing picker fatigue. Up to now, the studies related with picking time considered constant time for extraction. Additionally, some of them addressed the effects of human factors on picking efficiency in the concept of golden-zone retrieval in a narrow way. However, we think that human factors have a big impact on picking efficiency and needs to be analyzed in detail, at least in a theoretical way.

In manual order picking, it is not uncommon that a worker performs hundreds of picks from pallets and stacks them on a pallet jack to form an order. Workers access products by combinations of bending, extended reaching and twisting to various locations on a pallet (horizontally and vertically). Therefore, this kind of work environment is a high risk of low back disorders (LBDs) due to excessive stress that causes fatigue (Walder et al., 2007). According to Waters et al. (1995), 60\% of lost work days are caused by LBDs in food distribution warehouses. St-Vincent et al. (2005) studied on determinants of risks related to the manual materials handling in warehouse superstores. They categorized these determinants as the characteristics of equipment, products handled, workplace layout and work organization. Boonprasurt and Nanthavanij (2012) considered energy expenditure of workers to unload goods from a vehicle to model vehicle routing problem with a worker assignment. However, they assumed a fixed and known unloading time, and constant energy expenditure. Ucar and Bayrak (2015) examined several storage equipment such as flow racks and trolleys if they improve operation time and worker's fatigue in a warehouse and a supermarket. They conducted time study analysis to show their effects in two real cases. They concluded that using appropriate equipment does not only improve operation efficiency but also worker's ergonomic conditions. Davis et al. (1998) also investigated how different types of handle couplings affect spinal loading. They showed that handles reduce the risk of LBDs in manual materials handling when handles are designed into the cases that are commonly lifted from low levels. Marras et al. $(1997 ; 1999)$ analyzed the risk of occupationally related LBDs in depalletizing operations. They define the risk as a function of where a load is located on a pallet (see Figure 1a). In their study, pallets were divided into six regions based on possible occupational risk levels. They concluded that overall probability of LBD risk, which considers sagittal flexion, maximum moment, twisting and lateral velocity, increases significantly as one lifts from lower regions and more distant horizontal regions on a pallet. Marras et al. (1997) also determined that overall risk probability can increase from 0.4 in region A to 0.72 in region F (see Figure 1a for regions). Additionally, Marras et al. (1997) showed that regions B and F have the greatest risk value for lateral trunk while $\mathrm{C}$ has the lowest; regions $\mathrm{E}$ and $\mathrm{F}$ have the greatest trunk flexion angles while this risk increases monotonically from regions A to F. Neumann and Mebdo (2010) presented picking times of big boxes from different locations on a pallet by conducting video-based stopwatch analysis. Authors discussed that the reason of changing picking time of boxes is caused by biomechanical loading on spine and shoulders due to locations of boxes. Neumann and Mebdo (2010)'s analysis showed a similar result to Marras et al. (1999) with respect to the ergonomically risky regions on a pallet. 


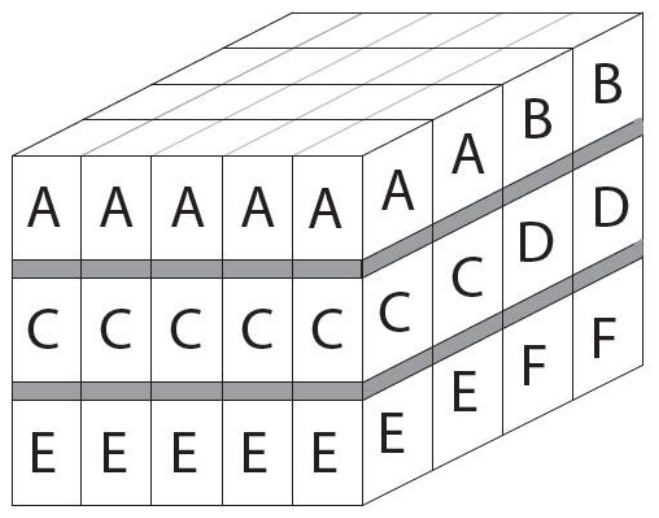

a) Position of cases.

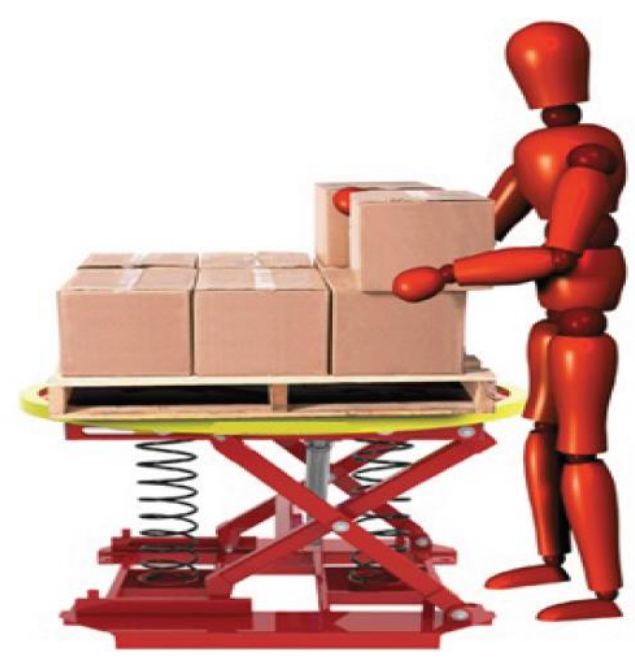

b) Raisable turntable.

Figure 1. Positions of cases on a pallet corresponding to the occupational risk levels and an example of usage of the turntable.

From the perspective of equipment selection, there are a number of ergonomic-assist devices to alleviate or eliminate that kind of ergonomic problems and also to increase the utilization of golden-zone retrieval in manual picking. As a simple and effective solution, Walder et al. (2007) suggested an adjustable height lift or a turntable for manual picking operations in order to reduce the excessive stress due to lifting, reaching, bending and twisting (see Figure 1b). Using this equipment, a pallet can be rotated to provide easy access to back cases by bringing them to the front. As cases are depleted, a pallet can be lifted to bring cases from lower levels to higher and easily accessible levels. Hence, this equipment also extends the use of golden-zone retrieval concept. Therefore, we think that raisable turntables can reduce both lateral trunk, sagittal flexion and load moment discussed by Marras et al. (1997), and can alleviate occupational risks in manual material handling. Hence, worker fatigue can also be reduced and productivity and work quality can be increased in a picking operation. Therefore, in this study, we investigate the effect of raisable turntable usage on manual picking (extracting) time in an order picking operation.

\section{Modeling of Picking Time}

Turntables are expected to alleviate workers' fatigue due to decreasing excessive stress to the low back and shoulders. Additionally, it is also expected to reduce picking time because it brings products closer to the worker for efficient and fast picking. Hence, all picks are realized from golden-zone. Therefore, in this section we develop a picking time model considering physical and physiological deterioration of humans with respect to worker fatigue in two systems: (1) manual extraction without using turntable, and (2) manual extraction with using turntable. For the sake of clarity, we call "traditional system" when workers perform picking operation manually without utilizing turntable equipment. If turntable is used to facilitate manual picking operation, we call it "turntable system."

In real life situations, processing time to accomplish a task may increase due to worsening conditions of a machine, a job or health conditions of a worker (Mosheiov, 1994). Hence, this situation is called "deterioration" in literature. We use deterioration in our study in a way that manual pickers become tired, exhausted or lose their strength and abilities during picking (loading) from (to) a pallet. The deterioration is defined in literature by a various forms of processing time function including linear, piecewise linear and nonlinear deterioration (see Alidaee and Womer (1999) for more details). Ozturkoglu and Bulfin (2012) used nonlinear deterioration to include effects of physiological factors of human such as oxygen consumption, heart rate and blood pressure in manual order picking activities. Hence, they studied on scheduling jobs and appropriate breaks on a single operator by considering human factors. We also decide to use nonlinear deterioration, in a similar way to Ozturkoglu and Bulfin (2012), in our study because of the accumulation effect of repetitive strain on the muscles, spine and lumbar during the motion for picking or loading operations, as well as because of psychological effects of repetitive motion. Additionally, we consider positions of cases as another deterioration factor in manual picking operation because Marras et al. $(1997 ; 1999)$ showed that positions of cases have a big impact on LBDs and worker fatigue. The model parameters for the expected time of picking cases on a pallet location are given in Table 1 . 
Table 1. The model parameters for calculation of picking time in traditional and turntable systems.

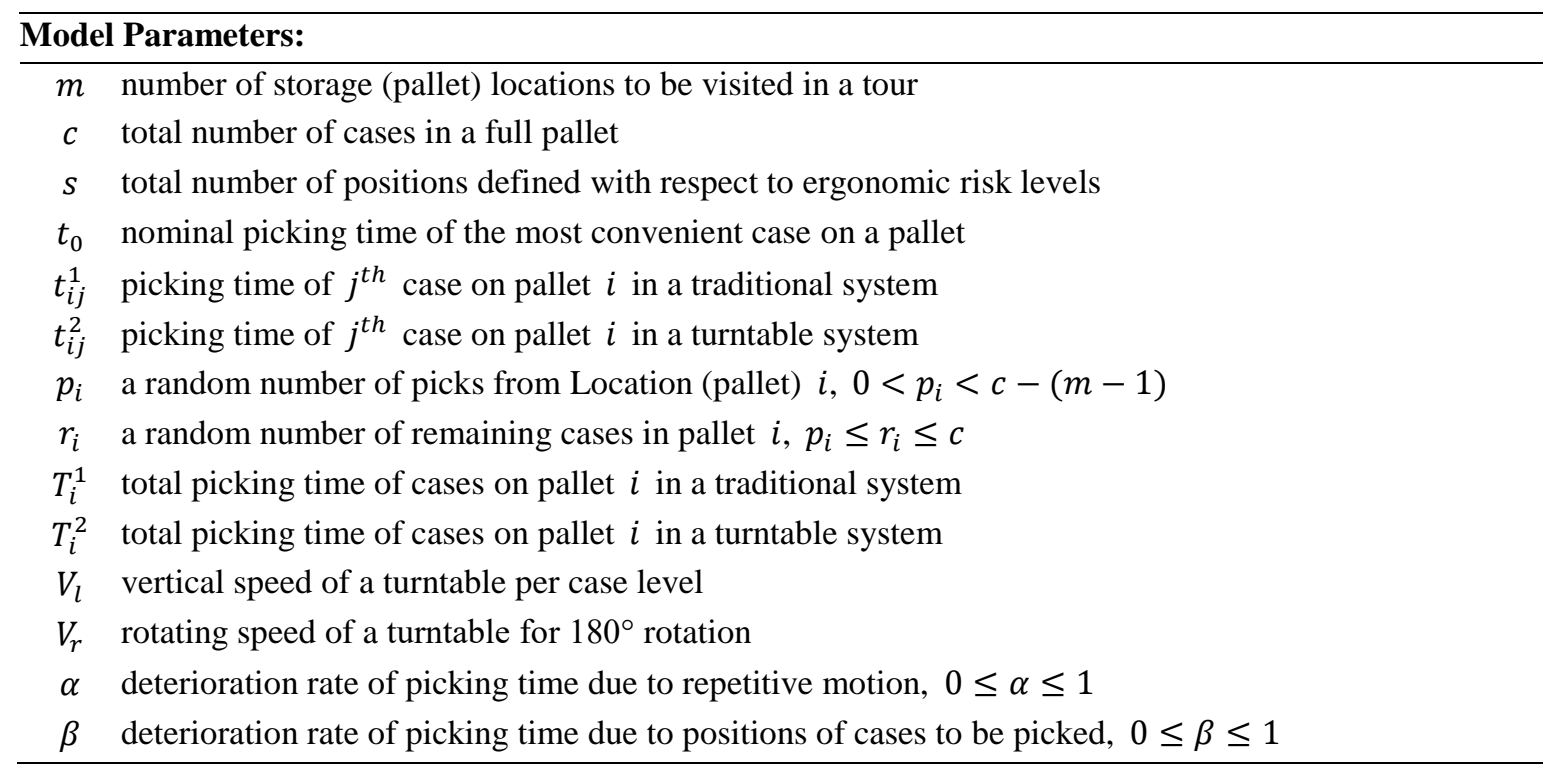

In our models, we assume that there is always sufficient time to replenish a location in a forward area prior to picking operation from there. The quantity per pick is less than a unit-load, hence case picking is realized. If a full pallet is required to be picked, it is picked from reserve locations. Additionally, we consider positions of cases on a pallet described by Marras et al. $(1997 ; 1999)$ in Figure 1a. Thus, there are six groups of cases $(s=6)$ which show difficulty levels of picking operation. Therefore, we use an increasing processing time function to pick a case based on both sequence of cases and their positions. In equations 1 and 2, the first terms show the picking time of the most convenient case that is located both at the front and at a comfortable height for an operator, usually at the waist level. The second terms are also common and they show the amount of deterioration caused by repetitive picking (loading) of cases on a pallet in a sequence until the required order is fulfilled. The third term in equation 1 represents the amount of deterioration in picking time due to picking from different ergonomically risk levels. We also assume that workers have a full recovery during traveling from one pallet location to another.

$$
\begin{gathered}
t_{i j}^{1}=t_{0}+t_{0} \cdot\left[(1+\alpha)^{j-1}-1\right]+t_{0} \cdot\left[(1+\beta)^{f\left(r_{i}-j+1\right)}-1\right], \\
t_{i j}^{2}=t_{0}+t_{0} \cdot\left[(1+\alpha)^{j-1}-1\right],
\end{gathered}
$$

where $f(q)=s+1-\lceil(q \cdot s) / c\rceil$, and it gives the risk level of a case that is picked in the first order. Additionally, $q$ is the number of available cases on a pallet before picking is realized. In constructing $f(q)$ for the traditional system, we assume that workers always pick from front to the back, and then from top to the bottom (regions A through $\mathrm{F}$ level by level in a proper sequence as in Figure 1a). Risk levels, from 1 to 6, are assigned to each region A through F, respectively. For example, if $c=48$ and $s=6$ in a square pallet, each region includes 8 cases. If there are 30 cases remained in that pallet, the first case to be picked places in region $\mathrm{C}$, and the risk level determinant, $f(q=30)$, is 3 . Therefore, total time to pick required number of cases on an ordinary pallet $i$ in both systems,

$$
\begin{gathered}
T_{i}^{1}=\sum_{j=1}^{p_{i}} t_{i j}^{1}, \quad \forall i=1, \ldots, m, \\
T_{i}^{2}=\sum_{j=1}^{p_{i}} t_{i j}^{2}+g\left(r_{i}, p_{i}\right), \quad \forall i=1, \ldots, m .
\end{gathered}
$$

where $g\left(r_{i}, p_{i}\right)$ is total time of adjusting a turntable for picking all required cases on a pallet. Because workers always pick cases from the most convenient position in the turntable system, turntables require some time to be adjusted so as to provide provide easy access to cases. Let $z_{1}$ and $z_{2}$ are initial and final positions of the first and the last cases to be picked on a pallet in the turntable system. Let $z_{1}=\left\lceil r_{i} \cdot s / c\right\rceil$ and $z_{2}=\left\lceil\left(r_{i}-p_{i}\right) \cdot s / c\right\rceil$. Hence, 


$$
g\left(r_{i}, p_{i}\right)=\left\{\begin{array}{lll}
\frac{z_{1}-z_{2}}{2}\left(V_{r}+V_{l}\right) & \text { if } & z_{1}, z_{2} \in 2 \mathbb{N} \text { OR } z_{1}, z_{2} \in 2 \mathbb{N}-1 \\
\left\lceil\frac{z_{1}-z_{2}}{2}\right\rceil V_{r}+\left(\left\lceil\frac{z_{1}-z_{2}}{2}\right\rceil-1\right) V_{l} & \text { if } \quad z_{1} \in 2 \mathbb{N} \text { AND } z_{2} \in 2 \mathbb{N}-1 \\
\left(\left\lceil\frac{Z_{1}-z_{2}}{2}\right\rceil-1\right) V_{r}+\left\lceil\frac{z_{1}-z_{2}}{2}\right\rceil V_{l} & \text { if } & z_{1} \in 2 \mathbb{N}-1 \text { AND } z_{2} \in 2 \mathbb{N}
\end{array}\right.
$$

Hence, if the first pick is done from region A and last pick is done from region $\mathrm{C}$, the turntable rotates 180 degrees and lifts one level up to bring all cases to the front of a worker. Until a full pallet is depleted completely, a turntable is rotated 3 times and lifted 2 times. Additionally, the turntable is moved 2 levels down for resetting. Hence, we can estimate unit time of using a turntable $(d)$ for picking one case as in Equation 6.

$$
d=\frac{3 V_{r}+4 V_{l}}{c}
$$

When reorganizing equations 3 and 4 by inserting equations 1 and 2, and substituting $f(q)$ with an approximation $f^{\prime}(q)=s+1-\left(\frac{q s}{c}+\frac{1}{2}\right)$, where $q=r_{i}-j+1$ for pallet $i$, we initiate to obtain approximation models of picking time in both systems, $\widetilde{T_{l}^{1}}$ for traditional and $\widetilde{T_{l}^{2}}$ for turntable systems, as

$$
\begin{gathered}
\widetilde{T_{l}^{1}}=\sum_{j=1}^{p_{i}}-t_{0}+\sum_{j=1}^{p_{i}} t_{0}(1+\alpha)^{j-1}+\sum_{j=1}^{p_{i}} t_{0}(1+\beta)^{s+\frac{1}{2}-\left(r_{i}-j+1\right) \frac{s}{c}}, \\
\widetilde{T_{l}^{2}}=\sum_{j=1}^{p_{i}} t_{0}(1+\alpha)^{j-1}+g\left(r_{i}, p_{i}\right) .
\end{gathered}
$$

The second and the third parts of Equation 7, and the first part of Equation 8 can be expressed as geometric series and written as

$$
\begin{gathered}
\widetilde{T_{l}^{1}}=\sum_{j=1}^{p_{i}}-t_{0}+\sum_{j=0}^{p_{i}-1} t_{0}(1+\alpha)^{j}+\sum_{j=0}^{p_{i}-1} t_{0}(1+\beta)^{s+\frac{1}{2}-\frac{s r_{i}}{c}}\left((1+\beta)^{\frac{s}{c}}\right)^{j}, \\
=-p_{i} t_{0}+t_{0} \frac{(1+\alpha)^{p_{i}}-1}{\alpha}+t_{0}(1+\beta)^{s+0.5-\frac{s r_{i}}{c}} \frac{1-(1+\beta)^{\frac{s p_{i}}{c}}}{1-(1+\beta)^{\frac{s}{c}}} \\
\widetilde{T_{l}^{2}}=t_{0} \frac{(1+\alpha)^{p_{i}}-1}{\alpha}+g\left(r_{i}, p_{i}\right) .
\end{gathered}
$$

Equations 9 and 10 give total picking time of cases on pallet $i$ for both traditional and turntable systems, respectively, if the required number of pick and the remaining number of cases are given for pallet $i$. Without loss of generality, we assume that workers make a full pallet during a tour by picking cases from $m$ different locations to maintain higher efficiency of using material handling equipment (forklift, transpallet, etc.) and reduce empty travel. Additionally, we assume that warehouse management utilizes randomized storage policy which is one of the most commonly used policy in warehouses due to its higher space utilization. Hence, because all storage locations have an equal probability to be visited in this policy, we can easily derive that the average number of cases to be picked from a pallet location has a value of $E\left[p_{i}\right]=c / m$. Similarly, we can assume that $r_{i}$ is also uniformly distributed between $p_{i}$ and $c$ in order not to face with shortage in picking. Hence, the average number of remaining cases on a pallet can be estimated as $E\left[r_{i}\right]=\frac{c+m c}{2 m}$. We can also approximate total time of adjusting a turntable for $c / m$ picks as $E[g]=d \frac{c}{m}$. When we replace $p_{i}$ with $E\left[p_{i}\right], r_{i}$ with $E\left[r_{i}\right]$, and $g\left(r_{i}, p_{i}\right)$ with $E[g]$ in equations 9 and 10, we present approximation models of total picking time of cases on a pallet in both systems as

$$
\begin{gathered}
\widetilde{T_{1}}=-\frac{c t_{0}}{m}+t_{0} \frac{(1+\alpha)^{c / m}-1}{\alpha}+t_{0}(1+\beta)^{s+0.5-\frac{s(m+1)}{2 m}} \frac{1-(1+\beta)^{s / m}}{1-(1+\beta)^{s / c}}, \\
\widetilde{T_{2}}=t_{0} \frac{(1+\alpha)^{c / m}-1}{\alpha}+\frac{3 V_{r}+4 V_{l}}{m} .
\end{gathered}
$$




\section{Experimentation On Picking Time}

In this section, we investigate whether there is a statistically difference between the approximation model and the main model. We then compare the traditional and turntable system to see if turntable usage makes any difference on picking time or not. Last, we investigate which factors or combinations of factors have an effect on picking time. In order to conduct these analyses, we conduct a full factorial design of experiment. The factors that we consider in the experiment and their levels are shown in Table 2. We use Minitab 16 Statistical Software in our statistical analysis.

Factors $\alpha, \beta, c, t_{0}$ and $m$ are designed to be independent variables that might have an effect on the dependent variable which is expected picking time in our study. Three levels are defined for each factor as Low, Medium and High. Levels of $\alpha$ and $\beta$ are chosen as $0.01,0.05$ and 0.1 in a respective order from lowest to the highest. As mentioned before $\alpha$ and $\beta$ are two different deterioration factors that cause an increment in picking time due to ergonomic issues. The levels of these factors are basically determined by fitness or physical capability of a worker, psychological and physiological conditions of a worker, sizes and weights of cases on a pallet, easiness of handling of cases, orientation of cases, and environmental conditions such as temperature, humidity, noise and light, or combinations of these elements. As the conditions of these elements worsen, levels of $\alpha$ and $\beta$ are expected to increase. A pallet size, $c$, is total number of cases that can be stored in a full pallet, and its levels are 24, 48 and 72. $t_{0}$, nominal picking time, has also three levels at 6,12 and 18 seconds to represent the difficulty of picking cases due to its weight, orientation or fitness level of a worker. For the number of visited locations in a tour $(\mathrm{m})$, three different values are determined as 3,6 and 12. Additionally, we assume that rotation speed of the turntable $\left(V_{r}\right)$ is 8 seconds for an $180^{\circ}$ rotation, that is equal to two turns. The vertical speed $\left(V_{l}\right)$ is also taken as 2 seconds per level. It is very common to see these speeds for general mechanized turntables or lift tables in industry. Their costs range from $\$ 1,000$ to $\$ 4,000$ with respect to its handling capacity, type of powered machines, and type of metal used to make it, etc.

In our experiments, while there are five factors at three levels in the traditional system ( $3^{5}$ experiments), there are $3^{4}$ experiments for turntable system due to absence of $\beta$. Each combination of experimental levels constitutes a problem instance. Ten replications of each problem instance are used in our experiments.

Table 2. Levels of factors considered in experiments.

\begin{tabular}{|c|c|c|c|c|c|}
\hline & \multicolumn{5}{|c|}{ Factors } \\
\hline Levels & $\boldsymbol{\alpha}$ & $\boldsymbol{\beta}$ & $\boldsymbol{c}$ & $\boldsymbol{t}_{\mathbf{0}}$ & $\boldsymbol{m}$ \\
\hline Low & 0.01 & 0.01 & 24 & 6 & 3 \\
\hline Medium & 0.05 & 0.05 & 48 & 12 & 6 \\
\hline High & 0.1 & 0.1 & 72 & 18 & 12 \\
\hline
\end{tabular}

In each problem instance we first randomly generate number of picks $\left(p_{i}\right)$ from a uniform distribution on $[1, c-m+1]$ for each of the $m$ different locations. Because there should be at least one pick from a location, the lower limit of the distribution is 1 . In order to maintain that total number of cases picked from $m$ locations equal to a full case $(c)$, we modify $p_{i}$ values multiplying by $c / P$, where $P=\sum_{i=1}^{m} p_{i}$. We then generate remaining number of cases on a pallet in location $i\left(r_{i}\right)$ from a uniform distribution on $\left[p_{i}+1, c\right]$ that guarantees that there are always more number of cases available than the required number of cases on the pallet.

We first aim to show if there is any difference of means between the approximation and the main model. In order to estimate the means of picking time from the main models given in equations 3 and 4 , we performed Monte Carlo simulation. For this, we first calculate average picking time of cases on a location for a single replication as $T_{1}=\frac{1}{m} \sum_{i=1}^{m} T_{i}^{1}$ and $T_{2}=$ $\frac{1}{m} \sum_{i=1}^{m} T_{i}^{2}$. Then, we perform 10 replications by generating different problem instances. After taking the average of $T_{1}$ and $T_{2}$ values obtained in 10 replications, we obtain the estimated average length of picking time on a pallet (location) as $\widehat{T}_{1}$ and $\widehat{T_{2}}$, respectively. Approximation models $\widetilde{T_{1}}$ and $\widetilde{T_{2}}$ in equations 11 and 12 are also evaluated for each combination of factor levels.

Last, we perform a two-sample $t$ test to analyze if two means of $\widehat{T_{1}}$ (average picking time in main model) and $\widetilde{T_{1}}$ (approximated picking time) are equal or not. Hence, the null hypothesis is that their means are equal, and the alternative is that they are not equal. We also perform the same test for $\widehat{T_{2}}$ and $\widetilde{T_{2}}$ using the same hypothesis. As the results of t-tests show in Table 3, p-values for both tests are greater than 0.05 , hence, there is no statistically significant evidence to reject both null hypotheses. Therefore, we can conclude that approximation models provide statistically similar results with their main models. The resulting box plots of mean picking time of the models are also shown in Figure 2. 
Table 3. Comparisons of approximations and models by two-sampled t-test analysis.

\begin{tabular}{|c|cccc|}
\hline & $\mathrm{N}$ & Mean & Std. Dev. & SE Mean \\
$\hat{T}_{1}$ & 243 & 189 & 241 & 15 \\
$\widetilde{T_{1}}$ & 243 & 192 & 254 & 16 \\
\hline
\end{tabular}

Estimate for difference $\quad-3.50676$

\begin{tabular}{|c|cccc|}
\hline & N & Mean & Std. Dev. & SE Mean \\
$\hat{T}_{2}$ & 81 & 172 & 205 & 23 \\
$\widetilde{T_{2}}$ & 81 & 183 & 245 & 27 \\
\hline
\end{tabular}

95\% CI for difference $(-47.65878 ; 40.64526)$

Estimate for difference

$-11.0606$

$\mathrm{T}$-Value $=-0.16, \mathrm{P}$-Value $=0.876, \mathrm{DF}=482$

95\% CI for difference $\quad(-81.1147 ; 58.9935)$

(a) $\hat{T}_{1}$ vs. $\widetilde{T_{1}}$

T-Value $=-0.31, \mathrm{P}$-Value $=0.756, \mathrm{DF}=155$

(b) $\hat{T}_{2}$ vs. $\widetilde{T_{2}}$

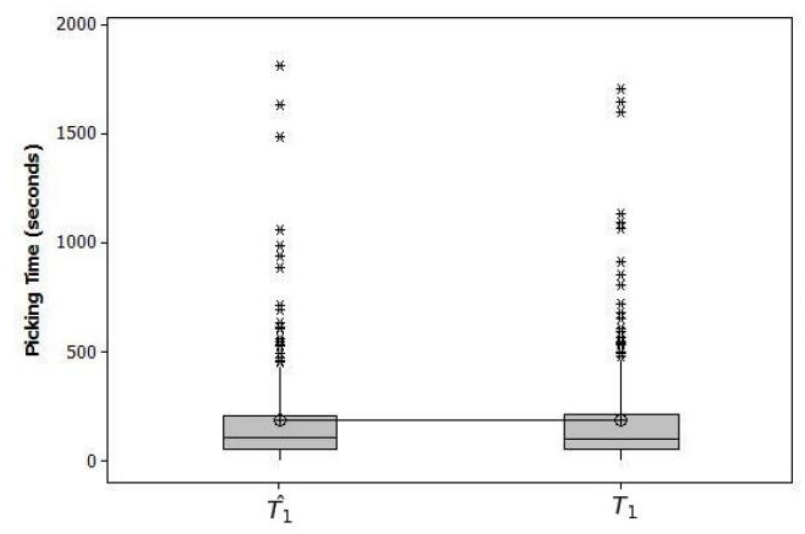

(a) Traditional

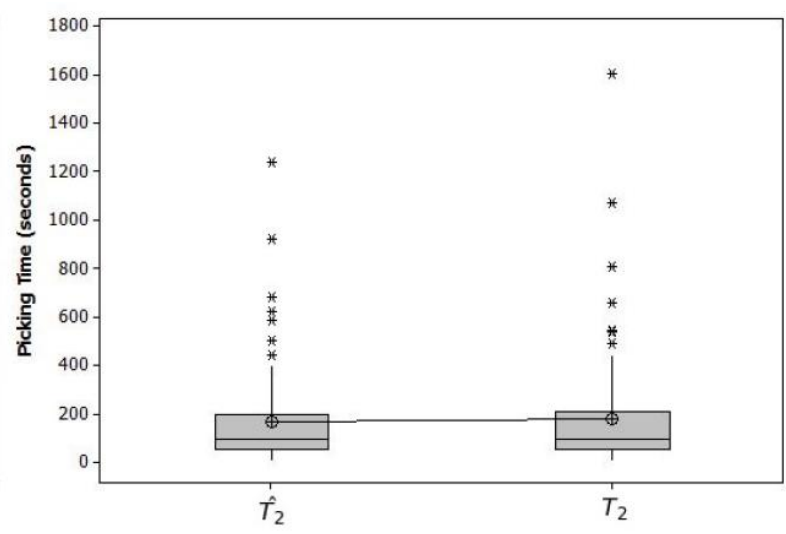

(b) Turntable

Figure 2. Box plots of the two sample t-tests.

Second, we investigate if there is any difference between average picking time in traditional and turntable systems by using the same design parameters and random number seeds discussed before. Hence, we perform an independent two sample t-test to analyze if there is any difference on the means of $T_{1}$ and $T_{2}$ using the 2430 samples including all replications $\left(H_{0}: \mu_{T_{1}}-\mu_{T_{2}}=0\right)$. We design the alternative hypothesis such that mean picking time of traditional system is greater than that of turntable system $\left(H_{1}: \mu_{T_{1}}-\mu_{T_{2}}>0\right)$. According to the test results given in Table 4 at $95 \%$ confidence level, we can conclude that the null hypothesis can be rejected because p-value is less than 0.05 . Hence, the alternative hypothesis is accepted that traditional system has statistically higher picking time than turntable system with respect to the higher portion of the sample data.

Table 4. Results of two-sampled t-test for comparison of traditional and turntable picking systems.

\begin{tabular}{|c|cccc|}
\hline & $\mathbf{N}$ & Mean & Std. Dev. & SE Mean \\
$\boldsymbol{T}_{\mathbf{1}}$ & 2430 & 189 & 272 & 5.5 \\
$\boldsymbol{T}_{\mathbf{2}}$ & 2430 & 174 & 259 & 5.3 \\
\hline
\end{tabular}
Estimate for difference
95\% lower bound for difference:

Last, using the same data set with 2430 instances, we perform a full factorial design of experiment to investigate the effects of factors on the difference of picking times of traditional and turntable systems at the $95 \%$ confidence level. The responses of the sample are designed as $T_{1}-T_{2}$. The null hypothesis for the main factors and their interactions are defined as there is no difference (significant effect) due to main factors, and interactions, respectively. The results of the full factorial design of experiment (the ANOVA table) are given in Table A.1 in Appendix. Main factors and their all level interactions explain $84.31 \%$ of total variation of the response $\left(R^{2}\right)$. Table A.1 shows which factors and their interactions explain how 
much variation on the response. As seen in the table, main factors $\beta, c, t_{0}$ and $m$ are significant on the model, and there is insufficient evidence of a difference between levels of $\alpha$ in terms of the difference of picking time because its p-value is greater than 0.05 (accept the null hypothesis). The reason of this is that $\alpha$ is the common term in both systems. Additionally, we also see that $\beta$ explains the biggest portion of the response due to its high sequential sum of square (Seq. SS.) value, as expected. The reason of this is that deterioration of the picking time due to locations of cases is only a factor in the traditional system.

Even though all two-way interactions of $\alpha$ are not significant on the model, it becomes significant at three way interactions. Especially when $\alpha$ interacts with $c$ and $m$ of which both strongly affect the number of cases picked from a single location. Therefore, the five-way interactions of the factors also become significant in the model. Because of this complex relationship and three-way and more interactions explain less amount of variance on the model than two-way and main factors alone, we develop a linear model including main factors and their significant two-way interactions using Response Surface Design analysis. Even though three-way and more interactions are omitted from the model, the new model still explains high amount of total variation of the response of which $R^{2}$ is $78 \%$. Relevant coefficients of this model with other statistical measures are given in Table 5.

As the coefficients of the model show in Table 5, $\mathrm{m}$ and its interactions have a negative impact on the picking time difference between traditional and turntable systems. Because increasing number of locations decreases the number of picks from a single location, the effect of deterioration on picking time decreases more in traditional system than that in turntable system. The reason of this is that the amounts of deterioration in traditional system caused by both repetitiveness and positions of cases, therefore both decreases simultaneously. As expected, this causes a diminishing effect of turntable usage on picking as the number of picks from a location decreases. Hence, adjustment time of turntable is not compensated enough to favor turntable usage with respect to picking time

Table 5. The predicted linear model of $\boldsymbol{T}_{\mathbf{1}}-\boldsymbol{T}_{\mathbf{2}}$ with maximum of significant two-way interactions.

\begin{tabular}{|c|cccc|}
\hline Term & Coefficient & SE Coefficient & T & P \\
\hline Constant & 14.6233 & 0.2496 & 58.579 & 0 \\
$\boldsymbol{\alpha}$ & -0.0711 & 0.3018 & -0.236 & 0.814 \\
$\boldsymbol{\beta}$ & 16.71 & 0.3045 & 54.878 & 0 \\
$\boldsymbol{c}$ & 9.7622 & 0.3054 & 31.963 & 0 \\
$\boldsymbol{t}_{\mathbf{0}}$ & 10.0598 & 0.3054 & 32.937 & 0 \\
$\boldsymbol{m}$ & -7.5575 & 0.2973 & -25.422 & 0 \\
$\boldsymbol{\beta} * \boldsymbol{c}$ & 8.5123 & 0.3696 & 23.029 & 0 \\
$\boldsymbol{\beta}^{*} \boldsymbol{t}_{\mathbf{0}}$ & 9.2681 & 0.3696 & 25.074 & 0 \\
$\boldsymbol{\beta} * \boldsymbol{m}$ & -8.5751 & 0.363 & -23.624 & 0 \\
$\boldsymbol{c} * \boldsymbol{t}_{\mathbf{0}}$ & 5.1447 & 0.3704 & 13.89 & 0 \\
$\boldsymbol{c}^{*} \boldsymbol{m}$ & -4.7347 & 0.3637 & -13.017 & 0 \\
$\boldsymbol{t}_{\mathbf{0}} * \boldsymbol{m}$ & -5.2535 & 0.3637 & -14.444 & 0 \\
\hline
\end{tabular}

In the meantime, as expected, $\beta, c$, and $t_{0}$ have positive contributions on the picking time difference. Hence, as the values of these factors increase, the turntable system is expected to outperform the traditional system. Especially as $\beta$ increases due to increasing weight of items, difficulty of bending and reaching or awkward position during the picking of cases from different positions, the turntable system provides greater advantage on expected picking time. The same effect is obviously seen when nominal picking time increases. The reason of this is that the amount of deterioration increases as the nominal picking time increases. Additionally, increasing number of cases on a pallet means increasing number of picks. Hence, the higher the number of picks is the greater the deterioration. Hence, as $c$ increases, it is normal to see that picking time in the traditional system increases more than that in the turntable system.

Although it is difficult to analyze the five-way interactions of the factors in this design because of mixed effects of these factors, we observe an interesting pattern in the levels of factors when we analyze the sample data in the experiment. Table 6 shows the levels of each factor within the full interactions that provide les expected picking time in the traditional system than that in the turntable system $\left(T_{1}<T_{2}\right)$. In this analysis, we consider the average value of responses in 10 replications. This observation shows that the traditional system is better than turntable system most of the time when $\beta$ is at the low level. 
However, as $\beta, t_{0}$, and $c$ increase, it seems that the turntable system becomes preferable. Especially for higher value of $\beta$, the turntable system outperforms the traditional system. According to our sample data, the traditional system is approximately $5 \%$ better than the turntable system in average when it is favorable $\left(T_{1}<T_{2}\right)$. However, the turntable system has $12 \%$ less expected travel distance than the traditional system in average when $T_{1}>T_{2}$. Hence, in general the turntable system presents approximately $7 \%$ improvement on the picking time over the traditional system in average in general. The changes in average percentage improvement $\left(100 \cdot \frac{T_{1}-T_{2}}{T_{1}}\right)$ and average difference with respect to change in the levels of each main factor is depicted in Figure 3.

Table 6. The levels of factors within the five-way interactions when $\boldsymbol{T}_{\mathbf{1}}<\boldsymbol{T}_{\mathbf{2}}$.

\begin{tabular}{|c|c|c|c|c|}
\hline $\boldsymbol{\alpha}$ & $\boldsymbol{m}$ & $\boldsymbol{\beta}$ & $\boldsymbol{c}$ & $\boldsymbol{t}_{\mathbf{0}}$ \\
\hline$\{\mathrm{L}, \mathrm{M}, \mathrm{H}\}$ & $\{\mathrm{L}, \mathrm{M}, \mathrm{H}\}$ & $\{\mathrm{L}\}$ & $\{\mathrm{L}, \mathrm{M}\}$ & $\{\mathrm{L}, \mathrm{M}, \mathrm{H}\}$ \\
\hline$\{\mathrm{L}, \mathrm{M}, \mathrm{H}\}$ & $\{\mathrm{L}, \mathrm{M}, \mathrm{H}\}$ & $\{\mathrm{L}\}$ & $\{\mathrm{H}\}$ & $\{\mathrm{L}, \mathrm{M}\}$ \\
\hline$\{\mathrm{L}, \mathrm{M}, \mathrm{H}\}$ & $\{\mathrm{L}, \mathrm{M}, \mathrm{H}\}$ & $\{\mathrm{M}\}$ & $\{\mathrm{L}\}$ & $\{\mathrm{L}\}$ \\
\hline
\end{tabular}

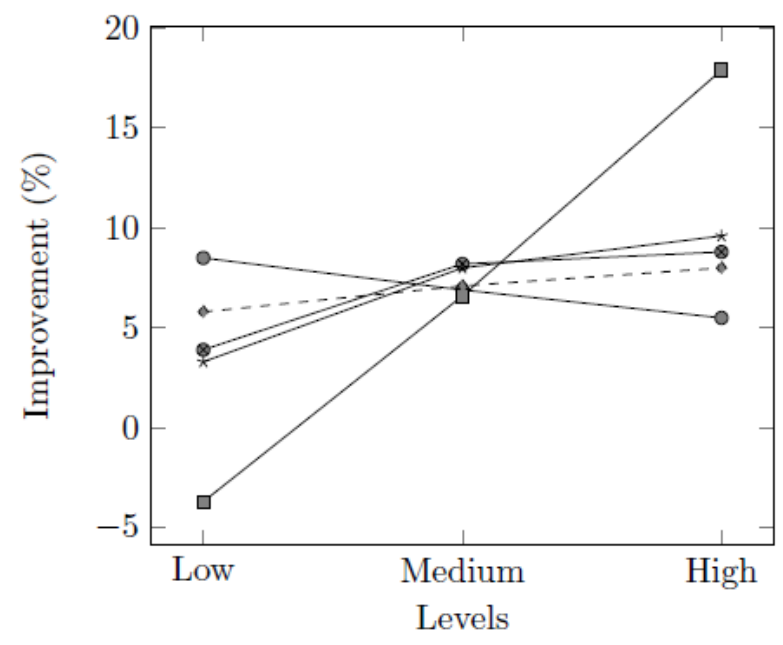

(a)
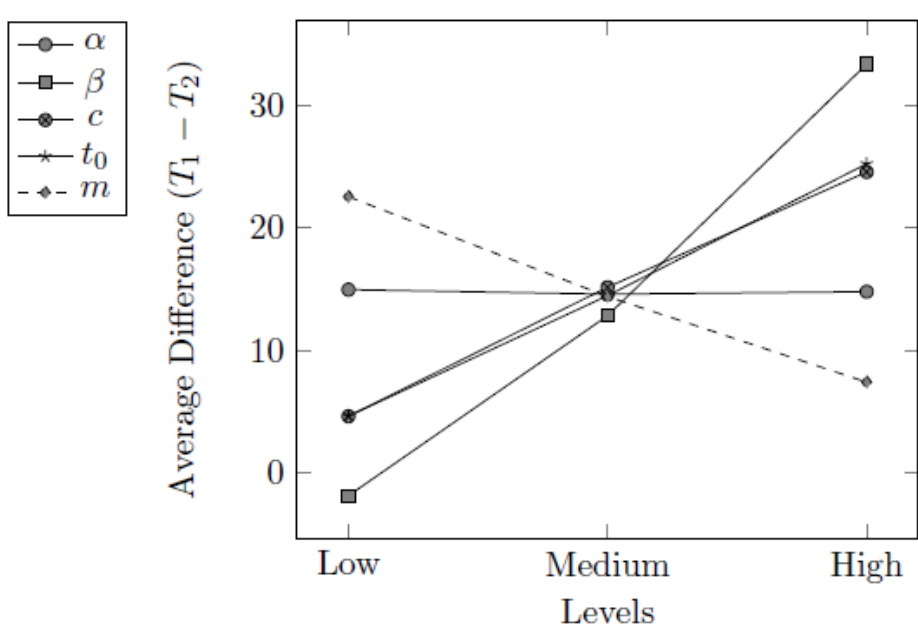

(b)

Figure 3. Effects of main factors on the picking time difference of the traditional and turntable systems.

It is interesting that the percentage of the improvement of turntable system slightly decreases as $\alpha$ increases. The reason of this is that $T_{1}$ increases as $T_{1}-T_{2}$ does not change at all. Another interesting result in Figure 3 is that increasing number of locations presents an increasing improvement on picking time by turntable system. Even though the picking time difference of traditional and turntable decreases mainly because of decreasing $T_{1}$ as $m$ increases, the percentage improvement seems to increase slightly because of the small value on the denominator.

\subsection{Extreme case: Loading a Full Pallet}

In industry, it is not uncommon that turntables are used for palletizing in part-to-picker order picking systems. In these systems, parts or cases are picked by automated devices and transferred to the picker through conveyors after sorted. At the end of the conveyor line, pickers load cases one by one to a pallet until it is full (see Figure 4 for a representation). Hence, in this section we focus on full pallet loading time. In order to analyze this case, it is enough to take $m=1$, because there is only one location. We can also assume that loading a pallet is the reverse operation of picking. In this case, the turnpallet is rotated and lifted until all cases are placed; hence it takes 32 seconds according to industry average times used before. 


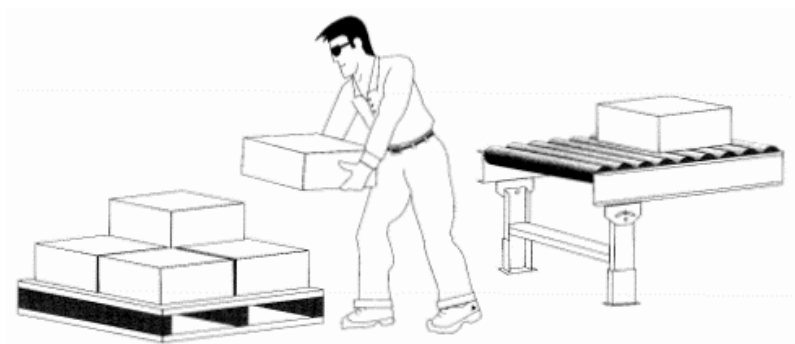

Figure 4. Representation of a full-pallet loading (this figure is obtained from Hytrol Conveyor Co. (1977)).

In Figure 5, the improvement of turntable system over traditional system is depicted according to ranked 4-way interactions of $\beta, \alpha, c$, and $t_{0}$, respectively. $\mathrm{L}, \mathrm{M}$ and $\mathrm{H}$ letters represent low, medium and high levels of factors at the $x$ axis. The dashed vertical line represent where the new level of $\beta$ interactions start. Hence, as expected, traditional system is better than turntable for all ways of interactions at the low level of $\beta$. Therefore, we can say that as long as benching and reaching do not cause deterioration on job or disorder on worker, usage of turntable does not provide any contribution. Even turntable causes a higher loading time. For example, the traditional system has $16 \%$ lower loading time for the interaction at lowest level of all factors, [L, L, L, L].

However, for interactions at the higher levels of $\beta$, turntable usage becomes preferable until a point where even a turntable can not provide any relief due to high amount of deterioration. This point can also be interpreted that the loading time of pallet is very long, about hours or days. Hence, this point is a critical point that might represent an injury or a musculoskeletal disorder of a worker causing a long delay of the job until a recovery. In the figure, this point is represented by $[\mathrm{H}, \mathrm{L}, \mathrm{H}, \mathrm{H}]$ where the positional deterioration is high due to greater bending and reaching, the loading deterioration is low due to physically fitness of a worker, high number of cases needed to be loaded, and high nominal loading time due to heaviness or big box sizes. At the level of $[\mathrm{H}, \mathrm{L}, \mathrm{H}, \mathrm{H}]$, the turntable system provides $20.6 \%$ less picking time than the traditional system.

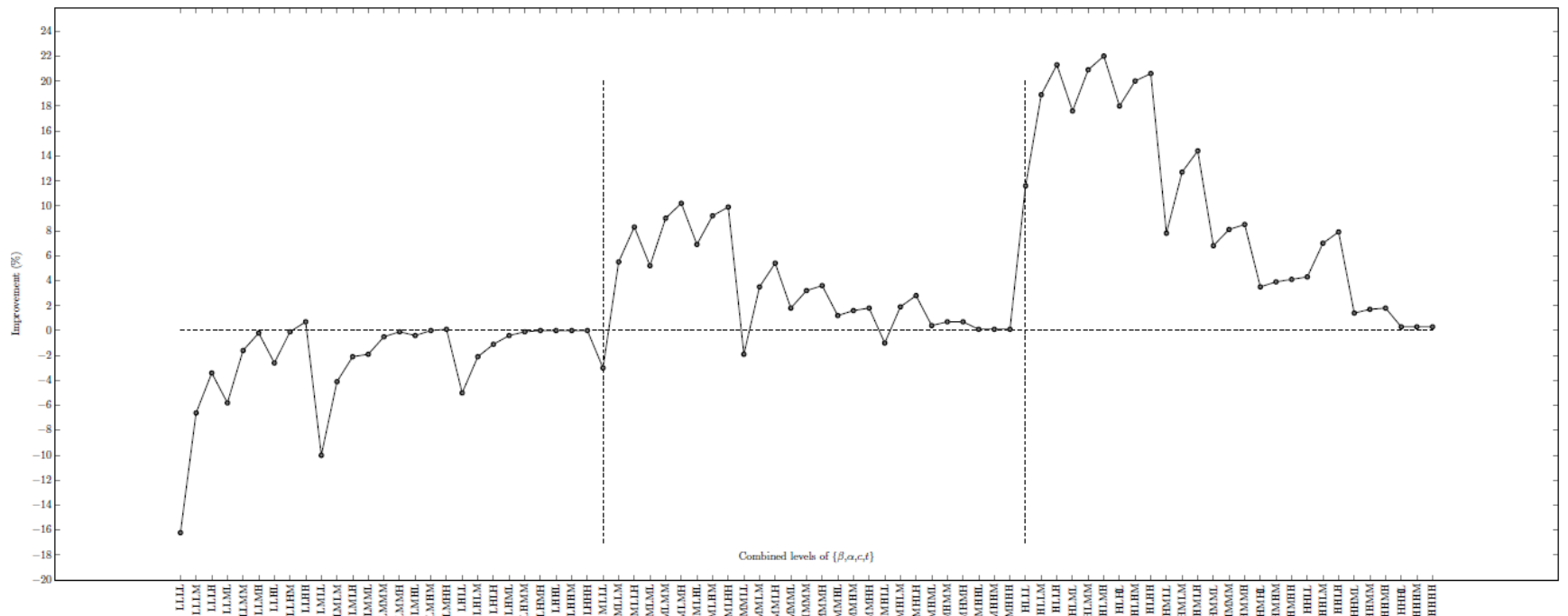

Figure 5. Effects of main factors on the difference of traditional and turntable system.

\section{Conclusion and Summary}

In this report, we discussed the effects of turntable usage on manual material handling operation in forward-picking area. We develop an analytical and an approximation model to estimate expected time to pick cases on a pallet considering ergonomics and human factors. In this model, we include the effects of both repetitiveness and positions of cases on the picking time. We also use variable picking time to indicate the deterioration of picking time due to fatigue and tediousness. We conduct a detailed experimental analysis to investigate the impact of design variables on the difference of picking times in the traditional and turntable systems. These experiments showed that the turntable usage offers savings over traditional manual handling system especially as the deterioration rate and the number of picks from a location increase. When deterioration of a job due to human factors is not really an issue, the turntable system even causes a higher picking time than traditional due to fixed 
adjustment time of the turntable. However, it is also known that even though turntable seems to have higher picking times for some cases, it can also provide unseen contributions to the work such as reduced low back pain, increase in productivity, increase in employee morale, decrease in work loss, etc. Additionally, we also implement the same model to provide insights for loading cases to make a full pallet at the point of shipping area. Last, considering that some turntables in industry are automatically adjusted, raised or lowered, by a weight control as long as boxes are loaded on it or picked from it. Hence, vertical speed or lifting time can be ignored for this type of turntables and we can expect that the savings would be more. 


\section{REFERENCES}

Alidaee, B., \& Womer, N. (1999). Scheduling with Time Dependent Processing Times: Review and Extensions. Journal of the Operational Research Society, 50(7), 711-720.

Bartholdi, J., \& Hackman, S. (2014). Warehouse and Distribution Science (Version 0.87 ed.). Atlanta, GA: Georgia Institute of Technology.

Boonprasurt. P., \& Nanthavanij, S. (2012). Optimal Fleet Size, Delivery Routes, and Workforce Assignment for the Vehicle Routing Problem with Manual Materials Handling. International Journal of Industrial Engineering: Theory, Applications and Practice, 19(6), 252-263

Davis, K., Marras, W., \& Waters, T. (1998). Reduction of Spinal Loading Through the Use of Handles. Ergonomics, 41(8), $1155-1168$.

deKoster, R., Le-Duc, T., \& Roodbergen, K. (2007). Design and Control of Warehouse Order Picking: A Literature Review. European Journal of Operational Research, 182, 481-501.

Frazelle, E. (1996). World-Class Warehousing. Atlanta, GA: Logistics Resources International.

Gademann, G., \& van de Velde, S. (2005). Order Batching to Minimize Total Travel Time in a Parallel-Aisle Warehouse. IIE Transactions, 37, 63-75.

Gademann, N., van den Berg, J., \& van der Hoff, H. (2001). An Order Batching Algorithm for Wave Picking in a ParallelAisle Warehouse. IIE Transactions, 33, 385-398.

Hytrol Conveyor Co. (1977). Basic Training Manual No. 3, Bulletin No 465, McKessock Engineering. Retrieved September 29, 2016, from http://www.mckessockconveyors.com/PDF/Hytrol/basictrainingmanual_3.pdf.

Jones, E., \& Battieste, T. (2004). Golden Retrieval: Stock Fast-Moving Inventory for the Highest Velocity. Industrial Engineer, 36(4), 37-41.

Marras, W., Davis, K., Allread, W., \& Jorgensen, M. (1997). Spine Loading and Probability of Low Back Disorder Risk as a Function of Box Location on a Pallet. Human Factors and Ergonomics in Manufacturing, 7(4), 323-336.

Marras, W., Granata, K., Davis, K., Allread, W., \& Jorgensen, M. (1999). Effects of Box Features on Spine Loading during Warehouse Order Selecting. Ergonomics, 42(7), 980-996.

Mosheiov, G. (1994). Scheduling Jobs Under Simple Linear Deterioration. Computers and Operations Research, 21(6), 653-659 .

Neumann, W., \& Medbo, L. (2010). Ergonomic and Technical Aspects in the Redesign of Material Supply Systems: Big Boxes vs. Narrow Bins. International Journal of Industrial Ergonomics, 40(5), 541-548.

Ozturkoglu, Y., \& Bulfin, R. (2012). Scheduling Jobs to Consider Physiological Factors. Human Factors and Ergonomics in Manufacturing and Service Industries, 22(2), 113-120.

Petersen, C., Siu, C., \& D.R., H. (2005). Improving Order Picking Performance Utilizing Slotting and Golden Zone Storage. International Journal of Operations and Production Management, 25(10), 997-1012.

Saccomano, A. (1996). How to Pick Picking Technologies? Traffic World, 13, 39-40.

St-Vincent, M., Denis, D., Imbeau, D., \& Laberge, M. (2005). Work Factors Affecting Manual Materials Handling in a Warehouse Superstore. International Journal of Industrial Ergonomics, 35, 33-46.

Tompkins, J., White, J., Bozer, Y., Frazelle, E., \& Tanchoco, J. (2003). Facilities Planning. New Jersey: John Wiley \& Sons.

Ucar, C., \& Bayrak, T. (2015). Improving In-plant Logistics: A Case Study of a Washing Machine Manufacturing Facility. International Journal of Industrial Engineering, 22(2).

Walder, J., Karlin, J., \& Kerk, C. (2007). Integrated Lean Thinking and Ergonomics: Utilizing Material Handling Assist Device Solutions for a Productive Workplace. Retrieved March 15, 2010, from http://www.mhia.org/downloads/industrygroups/lmps/whitepapers/Integrating_Lean_Thinking.pdf

Waters, T., Puts-Anderson, V., \& Baron, S. (1995). Health Hazard Evaluation Report No. 93-0920-2548. Nashville: NIOSH. Retrieved December 15, 2010, from http://www.cdc.gov/niosh/hhe/reports/pdfs/1993-0920-2548.pdf 


\section{APPENDIX A - FULL FACTORIAL DESIGN RESULTS}

Table A.1. Results of full factorial design of experiment for the difference of $\boldsymbol{T}_{\mathbf{1}}-\boldsymbol{T}_{\mathbf{2}}$

\begin{tabular}{|c|c|c|c|c|c|c|}
\hline Source & DF & Seq SS & Adj. SS & Adj. MS & $\mathbf{F}$ & $\mathbf{P}$ \\
\hline$\alpha$ & 2 & 56 & 56 & 28 & 0.24 & 0.788 \\
\hline $\boldsymbol{\beta}$ & 2 & 507981 & 507981 & 253991 & 2177.57 & 0 \\
\hline$c$ & 2 & 161299 & 161299 & 80649 & 691.44 & 0 \\
\hline$t_{0}$ & 2 & 171989 & 171989 & 85995 & 737.27 & 0 \\
\hline$m$ & 2 & 93074 & 93074 & 46537 & 398.98 & 0 \\
\hline$\alpha^{*} \boldsymbol{\beta}$ & 4 & 369 & 369 & 92 & 0.79 & 0.531 \\
\hline$\alpha^{*} c$ & 4 & 503 & 503 & 126 & 1.08 & 0.366 \\
\hline $\boldsymbol{\alpha}^{*} \boldsymbol{t}_{\mathbf{0}}$ & 4 & 240 & 240 & 60 & 0.51 & 0.725 \\
\hline $\boldsymbol{\alpha}^{*} \boldsymbol{m}$ & 4 & 85 & 85 & 21 & 0.18 & 0.947 \\
\hline$\beta * c$ & 4 & 79123 & 79123 & 19781 & 169.59 & 0 \\
\hline$\beta * t_{0}$ & 4 & 93394 & 93394 & 23349 & 200.18 & 0 \\
\hline$\beta * m$ & 4 & 88172 & 88172 & 22043 & 188.98 & 0 \\
\hline$c^{*} t_{0}$ & 4 & 28851 & 28851 & 7213 & 61.84 & 0 \\
\hline$c * m$ & 4 & 27164 & 27164 & 6791 & 58.22 & 0 \\
\hline$t_{0} * m$ & 4 & 33283 & 33283 & 8321 & 71.34 & 0 \\
\hline $\boldsymbol{\alpha} * \boldsymbol{\beta} * \boldsymbol{c}$ & 8 & 1183 & 1183 & 148 & 1.27 & 0.256 \\
\hline$\alpha * \beta * t_{0}$ & 8 & 395 & 395 & 49 & 0.42 & 0.908 \\
\hline$\alpha^{*} c^{*} t_{\mathbf{0}}$ & 8 & 1551 & 1551 & 194 & 1.66 & 0.103 \\
\hline $\boldsymbol{\alpha}^{*} \boldsymbol{\beta}^{*} \boldsymbol{m}$ & 8 & 142 & 142 & 18 & 0.15 & 0.996 \\
\hline$\alpha^{*} c^{*} \boldsymbol{m}$ & 8 & 2663 & 2663 & 333 & 2.85 & 0.004 \\
\hline$\alpha^{*} t_{\mathbf{0}} * \boldsymbol{m}$ & 8 & 338 & 338 & 42 & 0.36 & 0.94 \\
\hline$\beta * c * t_{0}$ & 8 & 16533 & 16533 & 2067 & 17.72 & 0 \\
\hline$\beta^{*} c^{*} \boldsymbol{m}$ & 8 & 12736 & 12736 & 1592 & 13.65 & 0 \\
\hline$\beta * t_{0} * m$ & 8 & 18103 & 18103 & 2263 & 19.4 & 0 \\
\hline$c * t_{0} * \boldsymbol{m}$ & 8 & 6664 & 6664 & 833 & 7.14 & 0 \\
\hline$\alpha * \beta * c * t_{0}$ & 16 & 2672 & 2672 & 167 & 1.43 & 0.118 \\
\hline$\alpha^{*} \beta^{*} c^{*} m$ & 16 & 3429 & 3429 & 214 & 1.84 & 0.022 \\
\hline $\boldsymbol{\alpha}^{*} \boldsymbol{\beta} * \boldsymbol{t}_{\mathbf{0}} * \boldsymbol{m}$ & 16 & 589 & 589 & 37 & 0.32 & 0.995 \\
\hline$\alpha * c * t_{0} * m$ & 16 & 4556 & 4556 & 285 & 2.44 & 0.001 \\
\hline$\beta * c * t_{0} * m$ & 16 & 5804 & 5804 & 363 & 3.11 & 0 \\
\hline$\alpha * \beta * c * t_{0} * \boldsymbol{m}$ & 32 & 7824 & 7824 & 244 & 2.1 & 0 \\
\hline Error & 2187 & 255091 & 255091 & 117 & & \\
\hline Total & 2429 & 1625855 & & & & \\
\hline
\end{tabular}

